\title{
New solutions for controlled compensating devices
}

\author{
Raxmatillo Ch. Karimov ${ }^{1, *}$, Akmal Egamov ${ }^{1}$, Shokhin Dzh. Dzhuraev ${ }^{2}$, Bakhadir Uzakov $^{3}$ \\ ${ }^{1}$ Tashkent state technical university named after Islam Karimov, Tashkent, Uzbekistan \\ ${ }^{2}$ Tajik technical university named after academic M.S.Osimi, Dushanbe, Tajikistan \\ ${ }^{3}$ Karakalpak State University, Nukus, Uzbekistan
}

\begin{abstract}
The article presents material, which is based on the results of the analysis of literature sources on automatic devices for regulating reactive power in power supply systems. In addition, this article provides information regarding the operability of the developed circuits of contactless devices and verification of the experimental study of the operation of installations with their use. Also presented is material about an experimental study of a contactless switching device for automatic power control of capacitor banks in various operating modes. A measuring device with programmed control "Fluke" was used to record and process experimental data of non-contact devices for regulating the power of capacitor banks. The results of experimental studies of a new device for automatic power control of capacitor banks, it can be stated that it fully meets the requirements.
\end{abstract}

\section{Introduction}

The most important priority of the sectoral structural policy is the dynamism of development and the increasing role of knowledge-intensive production. Orientation on the development of science-intensive and techno-intensive industries solves a strategic task - strengthening Uzbekistan's position in the world market, achieving economic and theological independence of the republic [1-3].

In the Republic of Uzbekistan, a course has been put forward for the development of society in the transition period to a market economy based on the development and reconstruction of existing enterprises for the production of both consumer goods and industrial goods of high quality that meet international standards. In the conditions of market relations, electric energy must be considered as a commodity that requires optimal management both at the production stage and so at the consumption stage. Under these conditions, for electricity, balance ratios are valid, including physical laws (such as Ohm's, Kirchhoff's, etc.) and variables and financial variables (tariffs, taxes, loans, etc.). The creation of these power generation and distribution models allows the constraints on physical and financial variables to be taken into account and studies to optimize and analyze the results of the solution under various conditions [1, 4-6].

\section{Relevance of the topic}

The successful solution of the most important problems of automation of production and consumption of high-quality electricity is possible only with the availability of first-class, reliable technical means of automating the regulation of reactive power $[1,4,7]$.

One of the directions of scientific and technological progress is the improvement of existing and the creation of new means of automation, in particular, automation of regulation of the power of capacitor banks. Automatic regulators as automation means, designed to control reactive power, convenient for transmission and consumption, find wider application both in power engineering and in automated voltage control systems of an electrical system [7-9].

It should also be noted that there is a lag in the creation of automatic devices for regulating the power of capacitor banks in comparison with foreign analogous samples due to the limited development of new technologies, the creation of both control circuit elements and capacitor banks. Therefore, at present, the development of schemes and tools is being accelerated, intended directly for automating the control of technological parameters. All this makes it possible to successfully complete the automation of all stages of research and to solve the problem of widespread introduction of automatic systems for regulating the power of capacitor banks [4-5, 6-7, 10-12].

\subsection{Reactive power compensation}

One of the main issues to be solved both at the design stage and at the stage of operation of industrial power supply systems is the issue of reactive power compensation, including the selection of expedient sources, the calculation and regulation of their power, the placement of sources in the power supply system [1-4, 7, 13-14].

The quantitative and qualitative changes taking place in

${ }^{*}$ Corresponding author

E-mail: raxmatillo82@mail.ru, dzhuraevsh@mail.ru 
industrial power supply in recent years make this issue of particular importance. At present, the increase in reactive power consumption significantly exceeds the increase in active power consumption. At the same time, the transfer of reactive power over considerable distances from the places of generation to the places of consumption significantly degrades the technical and economic indicators of power supply systems [2, 4, 15-16].

An increasing share in the total volume of total loads is occupied by abruptly variable and nonlinear loads with increased consumption of reactive power (valve converters for $\mathrm{DC}$ and $\mathrm{AC}$ drives, thermal installations, etc.). Under these conditions, the installation of capacitor banks without special measures to protect them from overloading by currents of higher harmonics may be unacceptable. To compensate for reactive power and ensure the required quality of electricity at a rapidly varying load, the presence of asymmetry and nonsinusoidality of the current and voltage waveforms, special filter-compensating and filter-balancing devices are being developed [4, 7, 15, 17-18].

In real conditions, the installation of filter compensating and filter balancing can lead to an unjustified increase in capital costs and to additional power consumption. Suffice it to say that the total installed capacity of these devices to ensure the required power quality can be commensurate with the load power that causes asymmetry or nonsinusoidality, and their dimensions and specific cost indicators can exceed the corresponding load indicators. Unfortunately, in [1, 4, 7] and other directive documents, many issues of reactive power compensation arising in the design and operation of power supply systems have not been adequately reflected. First of all, these are methodological issues of calculating the installed power and determining the location of compensating devices, protecting capacitors from overloads in nonlinear circuits, etc. [7, 11, 15, 19-21].

When choosing the optimal option, one should proceed from technical and economic calculations based on a systematic approach to the problem of reactive power compensation. This means that the optimal solution should satisfy the interests of both power supply systems and electricity consumers, taking into account the effect in the entire system as a whole $[1,15,18,21-22]$.

\subsection{New solutions for controlled compensating devices}

An increase in active loads at industrial enterprises is accompanied by a corresponding increase in reactive power consumption. In this regard, the problem of compensation and the most efficient distribution of reactive power is of great importance. A special place here is occupied by installations that allow practically inertia-free regulation of the generated reactive power. This refers to the use of bias reactors and valves with artificial commutation, devices with parallel connection of capacitance and adjustable inductance. The advantages of such compensators are the absence of rotating parts and the possibility of smooth and practically inertialess regulation of the output reactive power [22-24].

The use of artificial commutation in circuits of static compensating devices based on the use of electronic technology opens up new possibilities for high-speed regulation of reactive power and achieving high dynamic performance of reactive power compensation devices in power systems [1, 7, 11, 15, 24-25].

Currently, it becomes relevant to determine the areas of the most expedient application of various systems, controlled sources of reactive power and their technical and economic comparison with synchronous compensators and controlled capacitor units [1, 18, 24-26].

The creation of such rapidly adjustable sources of reactive power will make it possible to have installations that make it possible to change various reactive parameters of electrical systems without inertia. Installations of reactive power sources can be a powerful means of ensuring a stable voltage in networks supplying sharply variable loads at metallurgical plants with rolling mills, the presence of which unacceptably reduces the quality of voltage [15-18, 26-28].

The static device of reactive power sources consists of a capacitor bank and a special regulating element made of inductance with semiconductor valves. The total reactive power of such an installation $Q_{K}$ changes due to the variable component of the reactive power of the inductors $Q_{L}$, which is subtracted from the constant component of the reactive power of the capacitor bank $Q_{C}$ at a constant line voltage $U_{L}$ [4, 7, 11-12, 27-29]:

$$
Q_{\mathrm{K}}=Q_{\mathrm{C}}-Q_{\mathrm{L}}
$$

The capacities of the capacitor bank and inductors are selected in each specific case. In this case, the maximum power, equal to the power of the condensing unit, is supplied to the network with the valves closed. The power consumed by the circuit is maximum when the capacitor unit is off and is equal to the power of the reactors (inductors) when the valves are fully open [5-6, 13-15, 28-30].

The regulation of reactive power at sharply variable loads using reactive power sources is performed much faster than a synchronous compensator, since both the excitation system and the power element itself are practically inertial. At the same time, under the influence of reactive power sources, the voltage deviations on the buses from which these loads are supplied are reduced to about $2-2.5 \%$, while these deviations in the absence of reactive power sources can be $15-17 \%$. The positive influence of reactive power sources also affects the voltage at other points of the enterprise's power supply system, bringing the deviations at these points to $1-2 \%$ [31].

To obtain the most effective result from the generation of reactive power and voltage regulation in the $10 \mathrm{kV}$ network, which has frequent and large fluctuations, new automatic controlled reactive power sources were used, consisting of an unregulated capacitor unit and a regulating element of an inductance (reactor) with controlled semiconductor valves [7, 18, 21, 32].

Circuits with reactive power sources can also be used for phase regulation of the mains voltage. Since the scheme of reactive power sources is actually composed of three independent phases, then in case of asymmetry of the phase voltages of the network, this device can be used to equalize asymmetries by means of phase automatic control of reactive power $[18,33]$.

There are other circuits with valves and inductors that allow you to adjust the reactive power and mains voltage. Thyristor reactive power compensators of the TK-125-380UZ type are designed for reactive power compensation with automatic smooth maintenance of the power factor or voltage 
in alternating current networks with a voltage of up to $0.4 \mathrm{kV}$ and a frequency of $50 \mathrm{~Hz}$ in a temperate climate. Thyristor compensators are used in workshop substations and in industrial networks with an abruptly alternating (jerky) nature of the load, in networks with a rapidly changing nonprogrammable load curve (for example, in a network with single and group thyristor DC electric drives or with welding loads) [15, 26, 33-34].

Thyristor compensators can be used effectively in networks with any schedule of changes in reactive load in conjunction with capacitor units unregulated or with step regulation [11, 24-26, 35].

Thyristor reactive power compensators have a number of advantages, including automatic smooth maintenance of the set value of the power factor; high speed; smooth regulation of reactive power with limitation above the nominal value; the ability (due to the fast-acting smooth automatic compensation) to maintain the stability of the supply voltage. The nominal reactive power of the compensator is $125 \mathrm{kVAr}$, the nominal current is $190 \mathrm{~A}$, the voltage of the network is $380 \mathrm{~V}$, the value of the power factor settings is $0.3-1$, the power regulation range is $25-125 \mathrm{kVAr}$ [5, 6-7, 13-15].

Structurally, the thyristor compensator is also made in the form of a cabinet, the skeleton of which is a frame made of profiled steel, closed with a metal sheathing, and from the bottom - a mesh with holes for entering supply cables or buses. The expansion joint is serviced on both sides from the front and rear doors. For ease of maintenance, the automation elements are located block-by-block on panels, which are connected by plug connectors to the rest of the elements of the compensator circuit for half a mile [1, 7-8, 36].

\subsection{Automatic power control of capacitor banks by angle function $\varphi$}

A circuit is proposed for automatic regulation of the capacitor bank power directly as a function of the reactive power factor value, i.e. angle $\varphi$ - the angle between the vectors of the supply voltage and the load current. This method makes it possible to reduce the number of switching operations, since this angle changes significantly less than the load current and supply voltage, which improves the quality of work [12, 17, 23, 28].

Considering that a change in the consumed reactive power causes a change in the angle $\varphi$, it is proposed to use this device to control the state of the thyristor. To form a control pulse, a saturable current transformer is adopted, the primary winding of which is connected to the supply circuit. The magnetic core of the current transformer is made of a ferromagnetic material with an almost rectangular magnetization curve. Therefore, a peak-shaped electromotive force is induced on the secondary winding, which is necessary to control the state of the thyristor $\varphi[1,21,36-37]$.

As you know, the voltage of the supply network changes according to the law

$$
u=U_{m} \sin \omega t
$$

then $i=I_{m} \cdot \sin (\omega \cdot t+\varphi)$

Taking a ninth-order power function as an approximation of the magnetization curve, we have $[4-5,16,33]$ :

$$
i_{1} \omega_{1}=K \Phi^{9}
$$

Where $i_{1}$ - current of the primary winding of the current transformer; $\omega_{1}$ - is the number of turns; $K$ - coefficient of approximation; $\Phi$ - magnetic flux of the ferromagnetic core

We receive

$$
\Phi=9 \sqrt{\frac{\omega_{1}}{K} I_{m} \sin (\omega t+\varphi)} .
$$

After introducing the basic quantities in dimensionless form, we have $[4,7,11,21]$.

$\bar{U}=\bar{U}_{m} \sin \tau ; \quad \bar{i}_{1}=\bar{I}_{1 m} \sin (\tau+\varphi) ; \quad \bar{\Phi}={ }^{9} \sqrt{I_{1 m} \sin (\tau+\varphi)} ;$

here

$$
\begin{aligned}
& \bar{U}_{m}=\frac{U_{m}}{U_{6}} ; \quad \bar{I}_{m}=\frac{I_{1 m}}{I_{6}} ; \quad \Phi_{6}=9 \sqrt{\frac{I_{6}}{K} \omega} ; \\
& \bar{U}_{6}=\omega w \Phi_{6} ; \quad \tau=\omega e .
\end{aligned}
$$

If you accept $w_{1}=w_{2} ; I_{6}=I_{m}$, from the above we get

$$
\bar{i}_{1}=\sin (\tau+\varphi) ; \quad \bar{\Phi}={ }^{9} \sqrt{\sin (\tau+\varphi)} ; \quad \bar{u}_{2}=\frac{d \Phi}{d \tau} .
$$

Figure 1 shows the mains voltage and secondary voltage curves of a saturable current transformer. Curves $u_{2}=f(\tau)$ are obtained after numerical differentiation of the function $\bar{\Phi}=f(\tau)[4]$. From where the change in the shift of the peak-shaped pulse in relation to the shape of the voltage curve of the network, depending on the nature of the load, is clearly visible $[8-9,16,39]$.

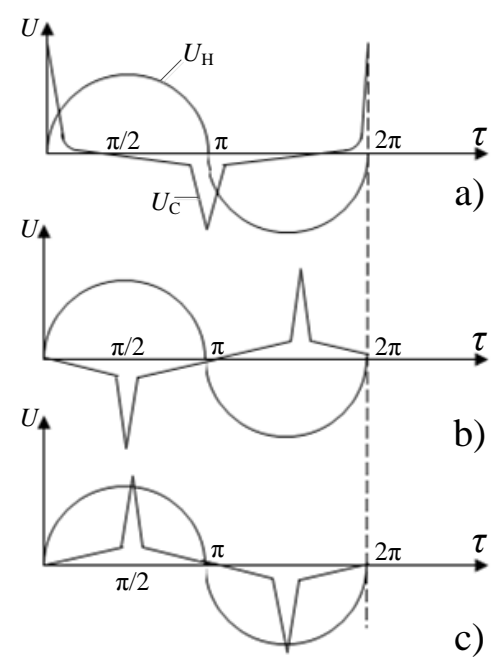

Fig.1. Dependencies $u_{\mathrm{z}}=f(\tau)$ and $u_{\mathrm{c}}=f(\tau)$ at $\varphi=0^{0}(\mathrm{a}) ; \varphi=70^{0}(\mathrm{~b})$; $\varphi=-70^{0}(\mathrm{c})$

This feature of the circuit can be used in the automatic power control circuit of a capacitor bank to generate control pulses and control the switching angle of the triode thyristor. When the nature of the load changes, the value of $\varphi$ changes from $13^{0}$ to $75^{\circ}$ degrees. When the value $\varphi$ changes from $0^{0}$ to $45^{0}$ degrees, the condensing unit does not turn on. When $\varphi=45^{0}$, the voltage relay gives a command to turn on the capacitor bank and the $\operatorname{tg} \varphi$ value decreases from 2,85-0,4 [6].

A schematic diagram of a single-stage automatic control of the capacitor bank power as a function of the angle $\varphi$ is shown in Fig.2 [7].

The executive unit is made in the form of a thyristor $T$ and a voltage relay $(\mathrm{KV})$ and a resistor $-R_{1}$ connected in parallel, through which the thyristor power electrodes are connected to the network. The regulating unit is made in the 
form of a saturable current transformer (TA), the primary winding of which is connected in series to the load, and the secondary winding through a series-connected diode and resistor - $R_{2}$ - to the control electrode of the thyristor of the executive unit $[7,11,18-21]$.

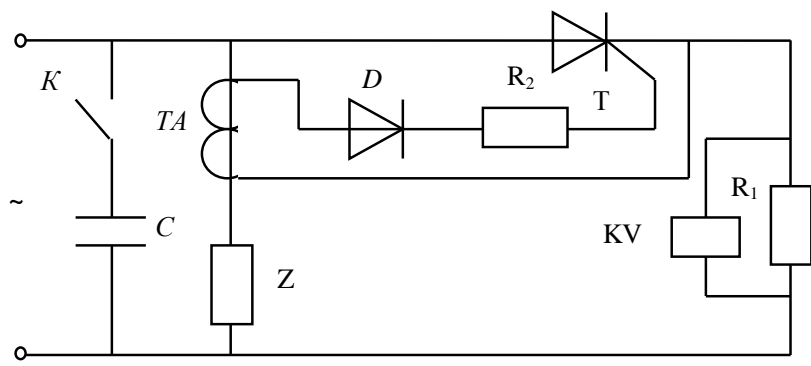

Fig.2. Capacitor bank switching control circuit

Changes in the value of $\varphi$ load causes a change in the firing phase of the thyristor. With an active load, the thyristor opening phase starts from $13^{\circ}$ and the maximum voltage is observed across the resistor $-R_{1}$. With an active-inductive nature of the load, the firing phase of the thyristor increases and this leads to a decrease in the voltage across the resistor $R_{1}$. With a voltage below a certain value, the KV relay, with its normally closed contacts, gives a signal to turn on the capacitor bank [7, 15-18].

With a decrease in the value of the angle $\varphi$, the switching angle of the thyristor decreases and the voltage across the resistor $R$ increases, and this causes an excess of the set voltage $\mathrm{KV}$, which will trigger the relay and give a signal to disconnect the capacitor bank from the network [7, 21, 28].

An experimental study of the device circuit was carried out with the following parameters of the elements: thyristor KU-202N; TA is made on the basis of a ring ferrite core with an outer ring diameter $\varnothing=70 \mathrm{~mm}$, inner $\varnothing=50 \mathrm{~mm}$, thickness $16 \mathrm{~mm}$. The number of turns of the winding $W_{1}=15, W_{2}=986$; voltage relay - RN 53/200; resistor $R_{1}=600 \mathrm{Ohm}, R_{2}=3$ $\mathrm{kOhm}$, diode $\mathrm{D} 226 \mathrm{~B}$. The active-inductive resistance connected in parallel is used as an active-inductive load.

\subsection{Experimental study of contactless device circuits}

Automatic power regulators of capacitor banks, which depend on the value of the phase angle $\varphi$ and at the same time on the voltage across the load, make it possible to increase the reliability and improve the quality of operation of electrical devices, to reduce the weight and dimensions [3$4,15,40]$.

Figures 3-5 show the characteristics of experimental studies of a device for automatic control of the power of capacitor banks in terms of the shift angle $\varphi$ and in voltage, which was created on the basis of the circuit shown in Fig.2.

For registration and processing of experimental data, a software-controlled apparatus "Fluke" was used. Curves of changes in current and voltage with a predominance of active load are shown in Fig. 3.

In this case, at $U=225$ Volts, the values of the consumed active and reactive powers were, respectively, $138 \mathrm{~W}$ and 28 VAr, and the value of the total power was $141 \mathrm{VA}$. With a decrease in the active load, the $\cos \varphi$ value decreases accordingly to the device pickup value $(\cos \varphi<0.95)$. In this case, the contactless regulator automatically connects the capacitor banks to the network. Each capacitor bank has a capacity of $1 \mu \mathrm{F}$ for a voltage of $\mathrm{U}=400 \mathrm{~V}$.

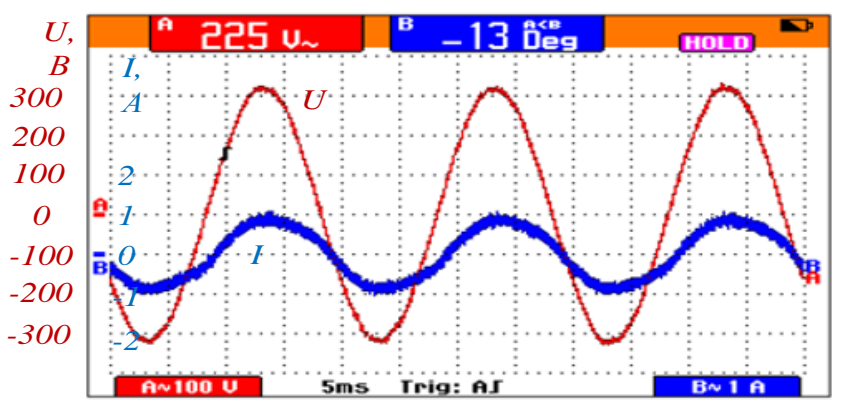

Fig.3. Curves of changes in current and voltage at $\varphi=13^{0}$

Further, the curves of current and voltage changes in each phase were investigated during the switching on of the capacitor banks $[1-4,15,24-26]$. Curves of voltage and current variation of the capacitor bank during the process of switching on the capacitor banks, phase A - with parameters is shown in Fig. 4.

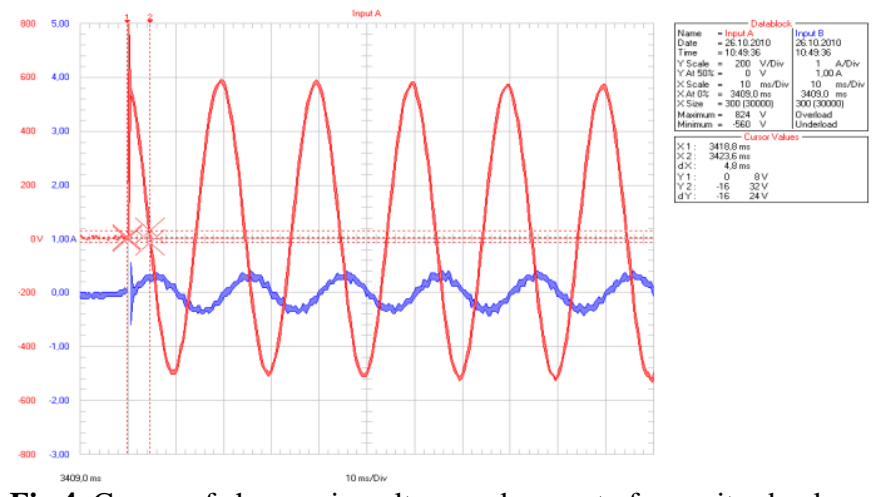

Fig.4. Curves of changes in voltage and current of capacitor banks

Curves of changes in voltage and current of a capacitor bank during a transient process when phase $\mathrm{A}$ is switched on - capacitor banks and electrical parameters are shown in Fig.5.

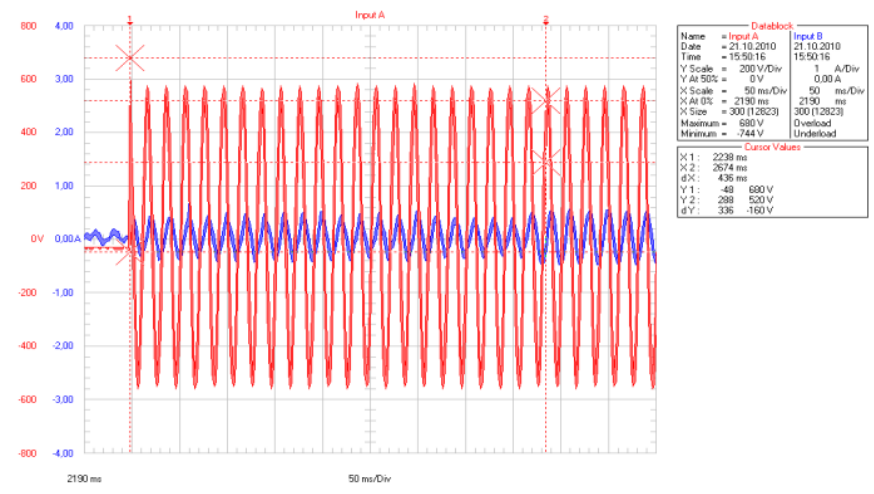

Fig.5. Transient process when switching on phase A - capacitor banks and electrical parameters

\section{Conclusions}

1. There are sufficient theoretical and informational materials for carrying out research work on the automation of power regulation of capacitor banks.

2. It is necessary to carry out experimental studies on the 
systematization of both individual elements and circuits for automatic power control of capacitor units in order to determine the control area.

3. Research is required to substantiate and agree on the performance characteristics of elements and devices used in automatic power control schemes for capacitor units.

4. As a switching semiconductor element of the automatic power control circuit of a capacitor bank, a thyristor with three outputs is recommended - triode thyristors.

5 . To reduce the number of switching operations, it is advisable to use automatic power control circuits of the capacitor bank directly as a function of the value of the reactive power factor, i.e. angle $\varphi$ - the angle between the vectors of the supply voltage and the load current.

6. To obtain a shift of the peak-shaped pulse in relation to the shape of the voltage curve of the network, depending on the nature of the load, the regulating unit is made in the form of a saturable current transformer, the primary winding of which is connected in series to the load, and the secondary winding through a series-connected diode and a resistor to the control electrode of the executive thyristor. block.

7. Taking into account the relevance of the creation and implementation of contactless devices for regulating reactive power, new circuits of such devices have been developed that work according to various principles and have simple designs.

8. A single thyristor circuit has been developed that operate as a function of the angle $\varphi$ and serve to regulate the power of capacitor banks.

9. Circuits of a voltage relay and a contactless starter have been developed for switching on capacitor banks, which operate as a voltage function and have compact overall dimensions.

10. A combined device for regulating the power of a capacitor bank has also been created, which turns on the capacitor banks and disconnects by the phase angle $\varphi$. It has small overall dimensions and is characterized by increased reliability.

11. The experimental scheme makes it possible to organize research with a wide range of changes (regulation) of the parameters of the circuit with a parallel connected active-inductive resistance - a biased load.

\section{References}

1. M.Sadullaev. Automatic power control of capacitor banks (Journal "Mining Bulletin of Uzbekistan", Navoi, Uzbekistan, 3. PP.76-77, 2006).

2. E.Usmanov, E.Kh.Abduraimov, R.Ch.Karimov. Using proximity relays to improve power quality (Journal "Bulletin of TSTU", Tashkent, Uzbekistan, 3-4, pp.48-51, 2012).

3. E.Usmanov, A.Rasulov, M.Bobojanov, R.Ch.Karimov. Non-contact voltage relay for switching windings of a boost transformer (E3S Web of Conferences, 139, 01079, 2019), https://doi.org/10.1051/e3sconf/201913901079

4. M.Sadullaev. Solution of differential equations of reactive power compensation (Journal "Mining Bulletin of Uzbekistan", Navoi, Uzbekistan, 3. PP.77-78, 2006).

5. Yu.M.Kurbonov, and others. Analysis of the influence of temperature on the operating mode of a photovoltaic solar station (IOP Conference Series: Earth and Environmental
Science, 614(1), 012034, 2020). doi:10.1088/17551315/614/1/012034

6. K.B.Nazirov, S.D.Dzhuraev, and others. Simulation of the Municipal-Household Electrical Supply System for Calculation and Forecasting the Level Current and Voltage Higher Harmonics (Proceedings of the 2020 IEEE Conf. of Russian Young Researchers in Electrical and Electronic Engineering, EIConRus 2020, pp.1276-1281, 9038935, 2020). DOI: $10.1109 /$ EIConRus49466.2020.9038935

7. T.M.Kadyrov, E.G.Usmanov, M.Sadullaev. Devices for automatic switching of capacitor banks (Patent of the Republic of Uzbekistan, IAP 04003, 29.07.2009)

8. Karimov R.Ch., Bobojanov M.K., Rasulov A.N., Usmanov E.G. Controlled switching circuits based on nonlinear resistive elements (E3S Web of Conferences, 139, 01039, 2019), https://doi.org/10.1051/e3sconf/201913901039

9. E.B.Saitov. Optimal model for additional operation of the storage system for photovoltaic wind power plants (E3S Web of Conferences, 220, 01080, 2020). https://doi.org/10.1051/e3sconf/202022001080

10. R.Karimov, and others. Modeling of kinematics and kinetostatics of planetary-lever mechanism (IOP Conference Series: Materials Science and Engineering, 883(1), 012129, 2020). doi:10.1088/1757-899X/883/1/012129

11. T.Kadyrov, E.Usmanov, M.Sadullaev. Regulation of capacity of capacitor banks as a function of voltage (Journal "Bulletin of TSTU", Tashkent, 1-2. PP.69-72, 2010).

12. E.B.Saitov, and others. Study of Solar Radiation and Wind Characteristics in Various Regions of Uzbekistan (E3S Web of Conferences, 220, 01061, 2020). DOI: 10.1051/e3sconf/202022001061

13. R.Karimov, and others. Reliability indicators of stabilizing devices in the agriculture electrical supply system (IOP Conf. Series: Materials Science and Eng., 883(1), 012142, 2020). doi:10.1088/1757-899X/883/1/012142

14. E.B.Saitov. Renewable Energy Development in Uzb.: Current Status, Problems and Solutions (E3S Web of Conf., 216, 01134, 2020). DOI: $10.1051 / \mathrm{e} 3$ sconf/202021601134

15. M.Bobojanov, M.Sadullaev. Non-contact device for regulating the power of capacitor banks (Journal "Mining Bulletin of Uzbekistan", Navoi, 4. PP.91-94, 2010).

16. R.Karimov, and others. Non-contact controlled voltage stabilizer for power supply of household consumers (IOP Conf. Series: Materials Science and Eng., 883(1), 012120, 2020). doi:10.1088/1757-899X/883/1/012120

17. S.Shoguchkarov, and others. The effect of the surface geometry of a photovoltaic battery on its efficiency (E3S Web of Conferences, 216, 01149, 2020). https://doi.org/10.1051/e3sconf/202021601149

18. M.K.Bobojanov, Z.O.Eshmurodov, M.Sadullaev. Experimental study of the operation of a low-power thyristor starter (Journal "Mining Bulletin of Uzbekistan", Navoi, Uzbekistan, 4. PP.64-67, 2011).

19. R.Karimov, M.Bobojanov. Analysis of voltage stabilizers and non-contact relays in power supply systems (E3S Web of Conferences, 216, 01162, 2020). https://doi.org/10.1051/e3sconf/202021601162

20. E.B.Saitov, and others. Networked interactive solar panels over the roof photovoltaic system (PVS) and its cost analysis at TSTU (E3S Web of Conferences, 216, 01133, 2020). https://doi.org/10.1051/e3sconf/202021601133

21. M.Sadullaev, R.Ch.Karimov, and others. Research of 
contactless switching devices for starting electric motors in power supply systems (International scientific journal «The Way of Science». Volgograd, 3(49), PP.23-25, 2018).

22. R.Karimov. Study of the state of the issue of increasing the quality of electric energy in the power supply systems (E3S Web of Conferences, 216, 01163, 2020). https://doi.org/10.1051/e3sconf/202021601163

23. I.Sapaev, and others. Matlab-model of a solar photovoltaic station integrated with a local electrical network (IOP Conference Series: Materials Science and Engineering, 883, 012116, 2020). doi:10.1088/1757-899X/883/1/012116

24. M.Sadullaev, R.Ch.Karimov, and others. Issues of starting capacitor banks in power supply systems (International scientific and practical conference "Patterns of development of modern natural science, engineering and technology". Belgorod, PP.189-191, 2018).

25. R.Karimov. Using optoelectronic noncontact voltage relay in electrical supply systems (Technical science and innovation, 2, 2019). uzjournals.edu.uz/btstu/vol2019/iss2/8

26. J.Toshov, E.Saitov. Portable autonomous solar power plant for individual use (E3S Web of Conferences, 139, 01087, 2019) https://doi.org/10.1051/e3sconf/201913901087

27. S.Dzhuraev, S.M.Sultonov, and others. Compensation of Higher Harmonics of Current in the Electric Power Systems Containing Loads with Nonlinear Volt-Ampere Characteristics (Proceedings of the 2020 IEEE Conference of Russian Young Researchers in Electrical and Electronic Engineering, EIConRus 2020, pp.1208-1213, 9039016, 2020). DOI: $10.1109 /$ EIConRus49466.2020.9039016

28. M.Sadullaev, M.Bobojanov, R.Ch.Karimov. Creation and experimental study of a non-contact device for automatic power control of capacitor banks (Scientific journal "Problems of Energy and Resource Saving", Tashkent, 3-4, 2021).

29. M.Bakhadyrkhanov, and others. Silicon Photovoltaic Cells with Clusters of Nickel Atoms (Applied Solar Energy "English translation of Geliotekhnika", 52(4), pp.278-281, 2016) https://doi.org/10.3103/S0003701X1604006X

30. Rasulov A.N., Karimov R.Ch. The Contactless Relay of Tension in System of Power Supply (EESJ, 4, pp.174-178, 2015), doi:10.12851/EESJ201508C05ART02

31. I.U.Rakhmonov, K.M.Reymov. Statistical models of renewable energy intermittency // RSES 2020. E3S Web of Conferences. $\quad 216 \quad 01167$. https://doi.org/10.1051/e3sconf/202021601167

32. I.U.Rakhmonov, N.N.Kurbonov. Analysis of automated software for monitoring energy consumption and efficiency of industrial enterprises // E3S Web of Conferences. $\quad 216 \quad 01178$. https://doi.org/10.1051/e3sconf/202021601178

33. F.A.Hoshimov, I.U.Rakhmonov, N.N.Niyozov. Technology to reduce energy costs in the electric steel melting shop // ENERGY-21. E3S Web of Conferences. 209 (2020) 07017. https://doi.org/10.1051/e3sconf/202020907017

34. A.Rasulov, R.Ch.Karimov. The Contactless Thyristor Device for Inclusion and Shutdown of Condenser Installations in System of Power Supply (EESJ, 4, pp.179-183, 2015). doi:10.12851/EESJ201508C05ART01

35. Bobojanov M.K., and others. Study of the efficiency of conveyors of mining transport systems of mining complexes (E3S Web of Conferences, 177, 03023, 2020). https://doi.org/10.1051/e3sconf/202017703023
36. A.Rasulov, and others. Graphical-analytical method for constructing load characteristics (E3S Web of Conf. 216, 01171, 2020). https://doi.org/10.1051/e3sconf/202021601171

37. S.D.Dzhuraev, and others. Calculation of Permissible Power of Synchronous Generators Functioning with Transformer Load (Power Technology and Engineering, 2018, 52(4), pp.466-473, 2018). DOI: 10.1007/s10749-018-0976-3

38. S.Dzhuraev, and others. Effect of additional capacities on transients recovery voltage in the short - Line - Fault regime (Proceedings of the 2019 IEEE Conference of Russian Young Researchers in Electrical and Electronic Engineering, ElConRus 2019, pp.1044-1046, 8657006, 2019). DOI: $10.1109 /$ EIConRus.2019.8657006

39. S.D.Dzhuraev, and others. Analysis of the results of higher harmonic modeling in the electric networks of the Republic of Taj. with various voltage levels (Proceedings of the 2018 IEEE Conference of Russian Young Researchers in Electrical and Electronic Engineering, ElConRus 2018, pp.611-616, 2018). DOI: 10.1109/EIConRus.2018.8317171

40. M.M.Ikromov, M.Ibaidullaev, R.Ch.Karimov. Review of a voltage regulator based on transistors in power supply systems (Universum: Tech. scien.: Elec. Scien. journal, 4(85), 2021). https://7universum.com/ru/tech/archive/item/11595 